\title{
Halit Ziya Uşaklıgil'in "Aşka Dair" Adlı Hikâyesini Empati (Duygudaşlık) Kuramı Bağlamında Çözümleme Denemesi
}

\author{
DR. ÖĞ. ÜYESİ TÜRKAN YEŞİLYURT*
}

Öz

Okur merkezli Empati (Duygudaşlık) kuramı, Theodor Lipps tarafından geliştirilmiştir. Lipps'e göre empati, bir insanın kendisini karşısındaki bir nesneye, örneğin bir sanat eserine yansıtması, kendisini onun içinde hissetmesi ve bu yolla o nesneyi özümseyerek anlaması sürecidir. Lipps, 1897 yılından sonraki çalışmalarında nesnelerin yanı sıra insanların algılanması sırasında da "einfühlung"un ortaya çıabileceğinden bahsetmiştir. Bu yazıda Halit Ziya Uşaklıgil'in "Aşka Dair" adlı hikâyesinin kahramanı Hafız Nevzat Efendi'nin bir kadına duyduğu aşk, daha doğrusu platonik aşk, tahlil edilmiştir. Bu tahlil için Empati kuramına yaslanılmıştır. Hafız Efendi aşkını, duygularını söze dökmeden, kadınla fiziksel bir yakınlık kurmadan yaşar. Hafız sevdiği kadınla empati kurarak onu özümser. Daha doğrusu kendi yerine onu ikame etmiş gibidir. Hafız, kendisi tarafından sevildiğinden haberi bile olmayan hasta kadınla gönlünde bir ve birliktedir. $\mathrm{Ne}$ var ki, hislerini yalnızca okuduğu ezanlara ve gazellere yansıtır. Kadının köyden ayrılışı üzerine sevdiği kadının varlığında kendini eriten Hafız Efendi, intihar eder.

Anahtar sözcükler: Aşk, empati, Halit Ziya Uşaklıgil, hikâye, platonik aşk.

\section{THE ANALYSIS ESSAY OF HALİT ZIYYA UŞAKLIGİL'S STORY “ABOUT LOVE” IN THE CONTEXT OF EMPATHY THEORY}

\section{Abstract}

Reader-centered Empathy Theory was created by Theodor Lipps. According to Lipps, empathy is the process in which a person reflects himself / herself on an object, such as a work of art, that he / she feels himself / herself within it and in this way he / she understands it by absorbing. Lipps, in his studies after 1897, mentioned that "einfühlung" might emerge during the perception of people as well as objects. In this article, the love of Hafız Nevzat Efendi, the hero of Halit Ziya Uşaklıgil's story "About Love", more precisely his platonic love was analyzed. Empathy Theory was used for this analysis. Hafiz Efendi lives his love

\footnotetext{
* Sinop Üniversitesi Fen-Edebiyat Fakültesi TDE Bölümü, turkanyes@gmail.com, orcid.org/0000-0003-3138-1339 Gönderim tarihi: 08.05.2019

Kabul tarihi: 01.06.2019
} 
without expressing his emotions and without having a physical intimacy with the woman. Hafiz internalizes the woman he loves by means of empathy. Rather, it seems as if he replaced her instead of himself. Hafiz is together with the sick woman who doesn't even know that she is loved by him. However, he reflects his feelings only to the azans and ghazals he recites. Hafiz Efendi who dissolved himself in the presence of the woman he loves commits suicide upon her departure from the village.

Keywords: Love, empathy, Halit Ziya Uşaklıgil, story, platonic love.

\section{GİRIŞ}

lice Ferney, aşkı yazmanın zorluğunu şöyle dile getirir: "Ne olursa olsun
konuşmak, aşkı sözcükler uzayına kaydetmek istiyoruz. Ne var ki, bu zor ve
kısıtlayıcı bir iş" (2005, s. 145). Aşkı yazmak böyle zorken, sözcüklere dökülmüş aşk üzerine yorum yapmak daha zor olsa gerek. Yine de, bu yazıda Halit Ziya Uşaklıgil'in âşık bir hafızı anlattığı "Aşka Dair" adlı hikâyesi Empati kuramı çerçevesinde tahlil edilmeye çalışılmıştır. Hikâyenin kahramanının sevdiği kadınla duygudaşlık kurarak "saf aşk" yolunda nasıl kendini yok ettiği ortaya konmuştur.

\section{EMPATI KURAMI}

Üstün Dökmen'in belirttiğine göre "empati” kavramının iki atası vardır: Almancadaki "einfühlung" ve Eski Yunancadaki "empatheia". Bu kavramı ilk kullanan Alman psikologlardan Theodor Lipps'tir. Lipps'e göre bir insanın, kendisini karşısındaki bir nesneye, örneğin bir sanat eserine, yansıtması, kendini onun içinde hissetmesi ve bu yolla o nesneyi kendi içine alarak anlaması sürecine "einfühlung" denir. Lipps, 1897 yılından sonraki çalışmalarında nesnelerin yanı sıra insanların algılanması sirasında da "einfühlung"un ortaya çıabileceğinden bahsetmiştir. Lipps, bir insan için üç tür bilgiden bahseder: nesnelere ilişkin, kişinin kendisine ilişkin ve diğer insanlara ilişkin. Diğer insanlara ilişkin bilgiyi elde etmenin yolu "einfühlung"dan faydalanmaktır. Bir insan karşısındaki diğer insana kendisini yansıtarak onu anlamaya çabalar. Bu şekilde karşısındakinin iç dünyasına nüfuz etme şansını yakalar. 1909 yılında Titchener ise "einfühlung" terimini eski Yunanca'daki "empatheia" kavramını esas alarak İngilizce'ye "empathy" olarak çevirmiştir. Empatiye

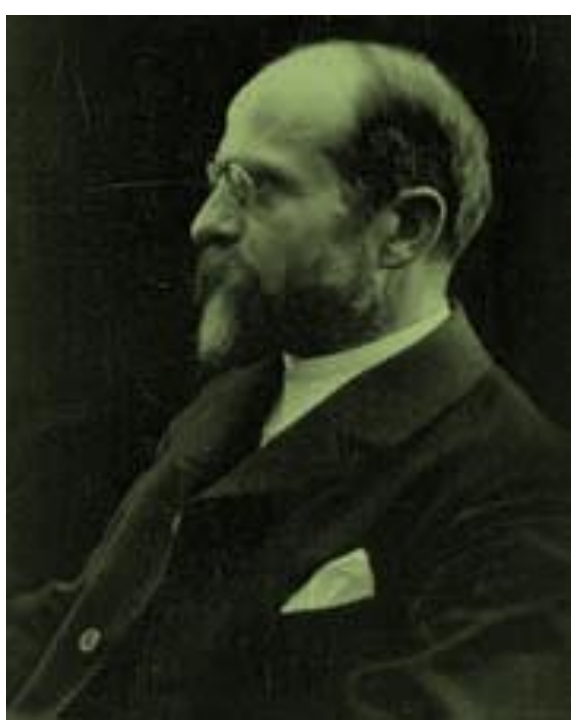

Theodor Lipps 
ilişkin tanımlar, yıllar boyunca üç ana aşamadan geçmiştir. Başlangıçtan 1950'lerin sonlarına kadar empati, bilişsel nitelikli bir terim olarak ele alınmış, empati ölçümü adı altında daha çok kişilerin birbirlerinin kişilik özelliklerini nasıl algıladıkları tespit edilmiştir. 1960'lı yıllarda empatinin bilişsel boyutunun yanı sıra duygusal boyutu da vurgulanmıştır; bu yıllarda, bir kişinin karşısındaki kişi gibi hissetmesi, empati kabul edilmiştir. 1970'lerde ise empati, daha dar anlamda kullanılmaya başlanmış, bir kişinin belirli bir duygusunu anlamaya ve durumu ona iletmeye empati adı verilmiştir (2017, s. 367-368).

Okur merkezli Empati (Einfühlung) kuramı da Theodor Lipps tarafından geliştirilmiştir. Buna göre empati, insanın nesneyle kurduğu ilişki sonucu onunla özdeşleşmesidir. Bu kurama göre insan nesneleri ruh durumuna göre niteler. Ali İhsan Kolcu'nun belirttiği gibi örneğin, yıkık bir ulu çınar karşısında duyduğumuz yücelik, çınara değil, kendimize ait bir duygudur; ne ki biz bu duyguyu çınar ağacında yaşarız (2016, s. 147). Yani kendimize ait özellikleri nesnelere yükleriz.

\section{AŞK}

Batı geleneğinde dört çeşit aşk vardır: Birincisi, seks veya şehvet olarak adlandırılan “libido"dur. İkincisi, yaratma dürtüsü olan “eros”tur. Üçüncüsü, dostluk, kardeş sevgisini ifade eden "philia"dır. Dördüncüsü ise Tanrı sevgisinin belirten "agapé" veya Latinlerin adlandırmasıyla "caritas"tır. Mustafa Said Kurşunoğlu'nun belirttiği gibi İbn Arabî'nin "hubb", "vedd" ve "1şk" kavramlarıyla antik Grek felsefesinin "eros", "philia" ve "agapé" kavramları arasındaki benzerlik dikkat çekicidir. Bu bağlamda "hubb" ile "eros", "vedd" ile "philia";"1şk" ile "agapé" zorluk çekilmeksizin eşleştirilebilir (2014, s. 24).

“Aşka Dair"in başkişisi, Hafız Nevzat Efendi'nin kadına duyduğu aşk, cinsel duygular barındırmayan "platonik aşk"tır. Ferdie Addis, bu aşk ile ilgili olarak şu değerlendirmeyi yapar:

Platon'un felsefesi MÖ 4. yüzyılda Atina'da yazılan Diyaloglar adlı eserinde anlatılmaktadır. En ünlü bölüm olan "Sempozyum”da (Şölen) Klasik Atina'nın önde gelenlerinin katıldığı sıra dışı bir akşam yemeğinin hikâyesi anlatılır. Yemek esnasında iyice sarhoş olan misafirler aşkın gerçek doğasıyla ilgili derin bir tartışmaya girer.

Misafirler arasında en göze çarpanı onca önemli özelliğine rağmen göründüğü kadarıyla doğanın en güzel varlıklarından biri olmayan filozof Sokrates'tir. Platon'a göre Sokrates şehirde çıplak ayakla dolaşan ve temizliğe önem vermeyen kaba saba bir adamdi.

Oysa Alcibiades kişisel bakımıyla ilgili tuhaf huylarına rağmen baştan çıkarıcılığıyla ünlü biriydi. Buna rağmen Sokrates, Alcibiades'in duygularını geri 
çevirmişti. Alcibiades, Sokrates'in kaba dış görünümünün arkasında yatan sıra dışı bilgeliği kavramış ve ona tam anlamıla âşık olduğunu itiraf etmişti.

Ancak o gece Alcibiades'in şanslı gecesi değildir. Platon'un anlattığına göre Sokrates gerçek içsel ve ruhsal güzelliği temel alan saf bir aşk olması için sadece fiziksel şehvetin ötesinde olan daha büyük gerçek aşkı keşfetmişti. Bu Platonik aşk çok derin ve felsefi bir tutkuydu, ancak kelimenin günümüzdeki kullanımı fiziksel bir ilişkinin olmadığını anlatır. (2016, s. 150-151)

Hafız Nevzat Efendi, gönlünü açmadığı, hiçbir fiziksel yakınlık yaşamadığı kadına "gerçek aşk", başka bir deyişle "saf aşk" ile bağlanır. Kendi içine çekilip kimseye dile getirmediği aşkını, yalnızca okuduğu ezanlara ve gazellere yansıtır.

\section{"Aşka Dair"}

Halit Ziya Uşaklıgil'in "Aşka Dair" adlı hikâyesinin ana karakteri Hafız Nevzat Efendi, askere giden arkadaşının yerine onun köyüne gelmiştir. Hafız; güzel sesli, çekingen, utangaç, genç bir adamdır. Müzikteki doğuştan gelen yeteneği nedeniyle birçok imkâna sahip olabileceği hâlde, müezzinlik yolunda, yoksul hayatın mahrumiyetlerinden zevk alır. Yaz başlarında, bir gün köye hava değişikliği için hasta, genç bir dul getirilir. Caminin civarında güneş gören bir eve yerleştirilir. Genç kadın, bütün gününü bahçede, bir sedirde güneş altında uzanarak veya kitap okuyarak geçirir. Köyde fazla kimse ile görüşmeyen Hafız, âşık olunca tamamıyla insanlardan

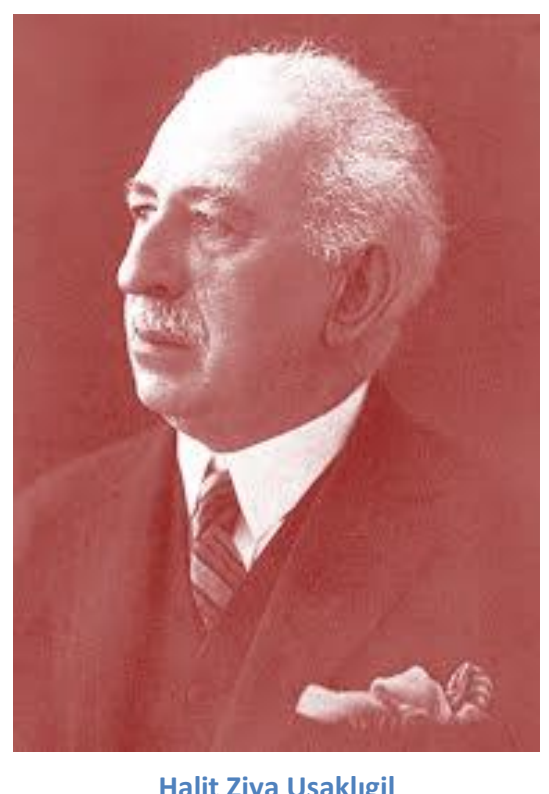

Halit Ziya Uşaklıgil kaçan bir kişiye dönüşür. Tek başına kırlarda gezip gazeller okur. Ezanı ağlıyor, inliyormuş gibi okumaya başlar. Yazın sonunda genç kadın köyü terk eder. Bunun üzerine ortadan kaybolan Hafız, ölü bulunur. O, intihar etmiştir.

Wilhelm Schmid'in dediği gibi "Her aşk önce bir mutlu tesadüfe muhtaçtır" (2017, s. 18). Hafız Nevzat Efendi, askere giden arkadaşının yerine müezzin olarak camiye, genç kadın ise hava değişikliği nedeniyle caminin civarındaki bir eve yerleşince, köye gelen Hafız ile hasta kadının karşılaşması gerçekleşir: “Hafız Nevzat'ın şerefede kaldığını, iki dirseğiyle kenara dayanarak ve çenesini avuçlarının içine alarak, gözleri evin bahçesinde düşündügünü, sonra birdenbire silkinip kaybolduğunu gördüm (Uşakligil, 2007, s. 19). Gerek "tebdil-i hava" için gelen hasta kadın gerekse askere giden arkadaşının yerine bir süreliğine camide müezzinlik yapmak için gelen Hafız geçici olarak köyde bulunmaktadır. Bu durum hayatın ve aşkın geçiciliğini ima etmektedir. 
Hafız hasta kadını gördükten sonra âdeta ona saplanıp kalır. José Ortega Y Gasset'nin belirttiği gibi o, "Saplanıp kalmış, katılaşmış, bir tek kişinin tutsağı olmuştur" (2017, s. 38). Bu saplanıp kalmanın sonucu olarak Hafız, yatsı ezanını okurken minareyi döneceğine yüzü hasta kadının penceresine karşı durur: "Kaç gece fark ettim, hep yatsı ezanını okurken minareyi devredeceğine yüzü muttasıl hasta hanımın penceresinde, sonra, ezan bitince, orada mıhlanıp kalıyor, dirseklerini dayayarak düşünüyor (Uşaklıgil, 2007, s. 20). Hafız, âşık olmasıyla birlikte yalnızca kadına saplanıp kalmaz, aynı zamanda kelimenin tam anlamıyla "merdümgiriz", insanlardan kaçan bir kişi olur.

Hafız Nevzat Efendi, acıyla dolayısıyla sevdiği kadının hastalığıyla da bütünleşir. Bell Hooks'un belirttiği gibi sevgi, mutluluktan daha çok acıdır: “Düzmece sevgi nosyonları bize sevgiyi hiçbir acı duymayacağımız, sabit bir mutluluk hâlinde var olacağımız bir yer olarak öğretir. Öncelikle bu inanışlardaki sahteliği açığa çıkarmak ve sevmeye başladığımızda dertlerin, acıların sona ermeyeceği gerçeğini görmek ve kabul etmek zorundayı" (2018, s. 154). Hafız, acıyı baştan kabul etmiştir: “Gazeline suzinak kararı vermişti; belki de bu acı şarkıyı okuyabilmek için 'Sûznâk-i âteş-i aşkım yetiş imdadıma' diye başladı" (Uşaklıgil, 2007, s. 21). Dilimize kolay geldiği için "sûzinâk" dediğimiz makamın asıl adı "sûznâk"tır. "Sûz; ateş, yakma; sûznâk ise yakan, yakıcı demek[tir]" (Parlatır, 2014, s. 1537).

Hafız'ı yakan kadına duyduğu aşktan başka bir şey değildir. Ömer Faruk Huyugüzel'in belirttiği gibi Hafız, aşkını okuduğu ezanlara yansıtır (2010, s. 100). Başka bir deyişle ezan duygularına tercüman olur: "Bu gece onun sesinde daha derinden ağlayan, inim inim inleyen bir eda vardı. İkide birde ezanın her lâhninde nağmeler uzana uzana, kıvrılıp büküle büküle yayılırken birdenbire ta sonunda ya boğularak tekrar başlayan bir feryat yahut bir hıçkırıkla tıkanıp düğümlenen bir hırıltı oluyordu" (Uşaklıgil, 2007, s. 20).

Wilhelm Schmid, sevenin benliğini geriye çekmesi gerektiğini söyler: "Sevmek, benliğini geride tutup onun yerine kendine şunu sormayı gerektirir. Ötekinin ihtiyacı nedir, ne düşünür, ne hisseder, eksiği nedir, ona ne verebilirim?" (2017, s. 69). Hafız, sevdiği hasta kadının aşkından gazel okur. Daha doğrusu gazel vasıtasıyla ağlar, sızlar, feryat eder. Onun yerine ölmek için Allah'a yalvarır: "Varayım yalvarayım boynuma takub kefenim" (Uşaklıgil, 2007, s. 21). Hafız, sevdiği kadınla özdeşleşip onun yerine ölmek ister.

Schmid, aşkın nefes alabilmesi için âşığın ruhunun esnek olması gerektiğini belirtir: "Aşkın ruhsal düzlemde nefes alabilmesi için, ruhun istiridye vasfına sahip olması gerekir, ruhun dişsal koşullara ve kendi iç durumuna bağlı olarak doğru anda açılabilmesi veya kapanabilmesi, çok şeyi değiştirir" (2017: 34). Nevzat Efendi, hasta, dul bir kadına âşık olmayı ayıp saydığından mı; arkadaşından emanet aldığı hafızlık görevinden mi; mahcup bir kişi olduğundan mı bilinmez, kendini kadına açamaz. Aşkı sadece kendi gönlünde yaşayan Hafız, genç kadın köyden ayrılınca nefessiz kalmış gibi olur. 
Roland Barthes, aşk ile intihar arasında bir bağ olduğunu ifade eder: "Aşk alanında intihar isteği çok sık duyulur: en ufak şey bu isteği getiriverir" (2000, s. 198). Hafız da özdeşleştiği kadının girdabına kapılır. Hasta kadının köyden gidişi, Hafız'ı intihara sürükler. Hafız'ın kendine kıydığı mekân, kadının kaldığı evin bahçesidir: "Bahçenin demir kapısının iki kanadı birden açılmıştı ve kapının başlığına takılmış bir sarık, bunun ucunda öne sarkmış çıplak bir baş ve sabahın yarı aydınlığında vuzuh ile beliren ıslak bir cübbe vardı. Cübbeden yavaş yavaş akan yağmur katreleri çıplak ayakların altında çamurlarda kalmış eski kunduralarının üzerine mebzul gözyaşları gibi muttasıl damlıyordu”' (Uşaklıgil, 2007, 22). Hafız, değiştirilmesi mümkün olmayan bir karar verir. Emil Michel Cioran'ın ifadesiyle söylersek “aşkın cenaze arabası"na (2016, s. 69) -inancına ters düştüğü hâlde- kendi isteğiyle biner.

Carrie Jenkins, aşk sözcügünü genellikle olumlu olarak yorumlamanın yanıltıcı olabileceğine dikkat çeker: “Aşk sözcüğü güçlü bir sözcüktür ve her zaman olumlu bir şekilde yorumlanmıştır. Bu sözcüğü kullanmak gerçekte korkunç bir durum olan şeyi maskeleyebilir" (2017, s. 178). Gerçekten de aşk, içinde birçok tehlikeyi barındırabilir. Kadının varlığında kendini eriten Hafız'ın onun yokluğunda kendi varlığına son vermesi anlamlıdır.

\section{SONUÇ}

Halit Ziya Uşaklıgil, “Aşka Dair” hikâyesinin kahramanı Hafız Nevzat Efendi âşık olur. $\mathrm{O}$, aşkını söze dökmeden, fiziksel bir yakınlık yaşamadan "saf aşk" olarak yaşar. Hafız sevdiği kadınla empati kurarak onu özümser. Daha doğrusu kendi yerine onu ikame eder. Hafız ve sevdiği kadın görünürde iki kişi, gerçekte ise Özdemir Asaf'ın 2=1 adlı şiirindeki gibi bir kişidir. Hafız, kendisi tarafından sevildiğinden haberi bile olmayan hasta kadın ile gönlünde bir ve birliktedir. Ne var ki, duygularını yalnızca okuduğu ezanlara ve gazellere yansıtır. Kadının köyden ayrılışı üzerine sevdiği kadının varlığında kendini eriten Hafız inancindan saparak intihar eder.

\section{KAYNAKÇA}

Addis, Ferdie (2016). Günlük Sohbetlerde Kullanılan Kavramların Kökenleri: Pandora'nın Kutusu. Çev. Berna Yılmazcan. Ankara: Akılçelen Kitaplar.

Barthes, Roland (2000). Bir Aşk Söyleminden Parçalar. Çev. Tahsin Yücel. İstanbul: Metis Yayınları.

Cioran, Emil, Michel (2016). Burukluk. Çev. Haldun Bayrı. İstanbul: Metis Yayınları.

Dökmen, Üstün (2017) Sanatta ve Günlük Yaşamda İletişim Çatışmaları ve Empati. İstanbul:

Remzi Kitabevi. 
Ferney, Alice. (2005) “Sevmekte Özgür Müyüz?”, Aşkın En Güzel Tarihi. Dominique Simonnet vd. Çev. Saadet Özen. İstanbul: Türkiye İş Bankası Kültür Yayınları, 133-149. Gasset, José Ortega Y (2017). Sevgi Üstüne, Çev. Yurdanur Salman. İstanbul: Yapı Kredi Yayınları.

Hooks, Bell (2018). Hep Aşka Dair: Yeni Vizyonlar. Çev. Umur İda. İstanbul: Notabene Yayınlar1.

Huyugüzel, Ömer Faruk (2010). Halit Ziya Uşaklıgil. Ankara: Akçă̆ Yayınları.

Jenkins, Carrie (2017). Aşk Nedir ve Ne Olabilir. Çev. Başak Öztürk. Ankara: Alabanda Yayınlar1.

Kolcu, Ali İhsan (2016). Edebiyat Kuramları: Tanım-Tenkit-Tahlil. Erzurum: Salkımsöğüt Yayınevi.

Kurşunoğlu, Mustafa Said (2014). Aşk'ın Ne'liğgi ve Kavramsal Doğası. Samsun: Etüt Yayınlar1.

Parlatır, İsmail (2014). Osmanlı Türkçesi Sözlü̆g̈̈̈. Ankara: Yarg1 Yayınları.

Schmid, Wilhelm (2017). Aşk Neden Bu Kadar Zordur ve Yine de Nasıl Mümkün Olur?. Çev. Tanıl Bora. İstanbul: İletişim Yayınları.

Uşaklıgil, Halit Ziya (2007). “Aşka Dair”, Aşka Dair. Haz. Özlem Nemutlu. İstanbul: Özgür Yayınları, 15-22. 